\title{
Uso de complemento lácteo em recém-nascidos a termo no ambiente hospitalar
}

Use of milk supplement in newborns at full term in hospital Uso de suplemento de la leche em recién nacidos a término en el hospital

Aline Celeste Zeferina ${ }^{1}$; Patrick Leonardo Nogueira da Silva ${ }^{2}$; Valdira Vieira de Oliveira ${ }^{3}$; Tadeu Nunes Ferreira ${ }^{4}$; Wilson Aguiar Filho ${ }^{5}$; Luciana Barbosa Pereira ${ }^{6}$

\section{Resumo}

O aleitamento materno exclusivo é uma prática que deve ser ofertada ao recém-nascido a termo obrigatoriamente até os seus seis meses de vida, porém a complementação láctea é realizada em situações específicas na qual contribui na continuidade do seu desenvolvimento. Este estudo objetivou analisar o uso do complemento lácteo em recém-nascidos a termo no ambiente hospitalar de uma cidade do norte de Minas Gerais. Trata-se de um estudo descritivo, exploratório, com abordagem quantitativa, realizado com 27 profissionais de maternidades de dois hospitais públicos. Foi utilizado um questionário estruturado para a coleta dos dados. Os mesmos foram digitados no programa Statistical Package for the Social Science e armazenados em tabelas. O tratamento se deu por meio de epidemiologia descritiva e análise exploratória dos dados. Quanto à caracterização dos profissionais que compunha a amostra, prevaleceu o sexo feminino, pediatras, tempo médio de trabalho entre cinco e nove anos. Em relação às indicações de complementação láctea, 100\% discordam totalmente quanto ao aleitamento misto de recém-nascidos cujas mães são soropositivas. Sendo assim, conclui-se que a principal razão reconhecida pelos profissionais para complementação ou substituição do aleitamento foram recém-nascidos cuja mãe é soropositiva.

Descritores: Aleitamento Materno, Alimentação Artificial, Leite Humano, Recém-Nascido.

\section{Abstract}

Exclusive breastfeeding is a practice that should be offered to the newborn term mandatory until their six months of life, but the milk supplementation is carried out in specific situations in which

\footnotetext{
${ }^{1}$ Graduação em Enfermagem pela Universidade Estadual de Montes Claros (UNIMONTES). Avenida Doutor Ruy Braga, s/nº, Vila Mauricéia, Montes Claros, MG, Brasil. CEP: 39.401-089. E-mail: alinneneo@ hotmail.com

${ }^{2}$ Especialista em Saúde da Família e Didática e Metodologia do Ensino Superior pela Universidade Estadual de Montes Claros (UNIMONTES). Enfermeiro da Secretaria Municipal de Saúde de Espinosa (MG). Avenida Juscelino Kubitscheck, s/nº, Santa Tereza, Espinosa, MG, Brasil. CEP: 39.510-000. E-mail: patrick_mocesp70@ hotmail.com

${ }^{3}$ Mestre em Ciências da Saúde (Área de Concentração em Ensino em Ciências da Saúde e Linha de Pesquisa em Saúde da Criança) pela Universidade Federal de São Paulo (UNIFESP). Professora do Departamento de Enfermagem da Universidade Estadual de Montes Claros (UNIMONTES). Avenida Doutor Ruy Braga, s/nº, Vila Mauricéia, Montes Claros, MG, Brasil. CEP: 39.401-089. E-mail: valdira_oliver@hotmail.com

${ }^{4}$ Mestrando em Tecnologia da Informação (Área de Concentração em Biologia Molecular Estrutural e Linha de Pesquisa em Biologia Computacional) pela Única Educacional (ÚNICA). Professor das Faculdades Unidas do Norte de Minas (FUNORTE). Avenida Osmane Barbosa, no 11.111, JK, Montes Claros, MG, Brasil. CEP: 39.404-549. E-mail: tadeu-nunes@hotmail.com

${ }^{5}$ Mestre em Saúde Pública (Área de Concentração em Política, Planejamento, Gestão e Práticas em Saúde e Linha de Pesquisa em Saúde Coletiva) pela Escola Nacional de Saúde Pública Sérgio Arouca (ENSP). Servidor Público da Fundação Oswaldo Cruz (FIOCRUZ). Rua Leopoldo Bulhões, ${ }^{\circ}$ 1.480, $7^{\circ}$ Andar, sala 705, Manguinhos, Rio de Janeiro, RJ, Brasil. CEP: 21.041-210. E-mail: aguiar.wilson@gmail.com

${ }^{6}$ Mestre em Ciências da Saúde (Área de Concentração em Ensino em Ciências da Saúde e Linha de Pesquisa em Saúde da Criança) pela Universidade Federal de São Paulo (UNIFESP). Professora do Departamento de Enfermagem da Universidade Estadual de Montes Claros (UNIMONTES). Avenida Doutor Ruy Braga, s/nº, Vila Mauricéia, Montes Claros, MG, Brasil. CEP: 39.401-089. E-mail: lubper@ hotmail.com
} 
ISSN 2179-6750

contributes to the continuity of its development. This study aimed to analyze the use of milk complement in newborn term infants in the hospital in a northern city of Minas Gerais. This is a descriptive, exploratory study with a quantitative approach, performed with 27 professionals from two public maternity hospitals. A structured questionnaire was used for data collection. They were entered into the Statistical Package for the Social Sciences and stored in tables. The treatment is given by descriptive epidemiology and exploratory data analysis. As for the characterization of the professionals who made up the sample, females prevailed, pediatricians, average working time between five and nine years. In relation to milk supplementary indications, $100 \%$ totally disagree as to mixed feeding of infants whose mothers are HIV positive. Therefore, it is concluded that the main reason recognized by professionals to complement or replacement of breastfeeding were newborns whose mother is HIV positive.

Key-words: Breast Feeding, Bottle Feeding, Milk Human, Infant Newborn.

\section{Resumen}

La lactancia materna exclusiva es una práctica que debe ser ofrecido al recién nacido a término obligatoria hasta los seis meses de vida, pero la suplementación de la leche se lleva a cabo en situaciones específicas en las cuales contribuye a la continuidad de su desarrollo. Este estudio tuvo como objetivo analizar el uso del complemento de la leche en los bebés nacidos a término en el hospital en una ciudad del norte de Minas Gerais. Se trata de un estudio descriptivo, exploratorio con enfoque cuantitativo, realizado con 27 profesionales de dos maternidades públicas. Un cuestionario estructurado se utilizó para la recolección de datos. Fueron introducidos en el paquete estadístico para las Ciencias Sociales y se almacenan en tablas. El tratamiento se administra por la epidemiología descriptiva y análisis exploratorio de datos. En cuanto a la caracterización de los profesionales que componen la muestra, predominio del sexo femenino, pediatras, duración media del trabajo entre cinco y nueve años. En relación con la leche indicaciones suplementarias, 100\% totalmente en desacuerdo en cuanto a la alimentación mixta de los bebés cuyas madres son VIH positivos. Por lo tanto, se concluye que la principal razón reconocida por los profesionales para complementar o sustitución de la lactancia materna eran recién nacidos cuya madre es VIH positivo.

Palabras-claves: Lactancia Materna, Alimentación Artificial, Leche Humana, Recién Nacido.

\section{Introdução}

A promoção, proteção e apoio ao aleitamento materno (AM) é uma das ações prioritárias da Área Técnica de Saúde da Criança e AM, fazendo parte do elenco de estratégias para a redução da mortalidade infantil, compromisso assumido pelo Brasil nos âmbitos internacional e nacional, por meio do Pacto de Redução da Mortalidade Materna e Neonatal 1. Para atingir este propósito, diversas estratégias de intervenções têm sido adotadas pela Política Nacional de Incentivo ao AM. Entre essas, no que se refere ao nível terciário de atenção a saúde, figura-se a Iniciativa Hospital Amigo da Criança (IHAC), que visa promover, proteger e apoiar o AM e contribui para o resgate do direito da mulher de aprender e praticar a amamentação com sucesso ${ }^{2}$. A IHAC é considerada uma das ações mais eficazes na promoção do AM ao propor rotinas hospitalares facilitadoras, através do 
ISSN 2179-6750

seguimento dos dez passos para o seu sucesso ${ }^{3}$

No entanto, apesar de todos esses esforços, ainda encontramos baixos indicadores de AM exclusivo (a criança recebeu somente leite materno sem quaisquer outros líquidos ou alimentos, exceto medicamentos), que apresentou uma media de prevalência de 37,9\% em crianças menores de seis meses na capital mineira. A partir dos seis meses de idade acrescenta-se uma alimentação complementar adequada, mas continuando a amamentação por dois anos ou mais, este estágio do AM apresentou prevalência de 50\% entre crianças de 9-12 meses também em Belo Horizonte. De modo que o desmame precoce constitui-se um desafio a ser enfrentado por todas as esferas de atenção à saúde, sendo este considerado um evento social, estando associado a vários fatores, entre eles, a introdução precoce de fórmulas lácteas ou outros alimentos para a criança ${ }^{4,1}$.

Na realização de um estágio voluntário, em atendimento a consulta puerperal, pôde-se reconhecer uma dessas práticas quando, na entrevista às mães, boa parte delas relatou que o complemento lácteo havia sido prescrito para o seu bebê, apesar das instituições serem credenciado na IHAC, cuja proposta evidencia que a complementação alimentar para recém-nascidos $(\mathrm{RN})$ deve ser feita apenas quando existe uma razão médica aceitável para essa prática ${ }^{5,6}$. Diante disso surgiu o seguinte questionamento: Quais têm sido as razões para o uso de complemento lácteo em $\mathrm{RN}$ a termo?

Portanto, este estudo objetivou analisar o uso do complemento lácteo em RN a termo no ambiente hospitalar.

\section{Métodos}

Trata-se de um estudo descritivo, exploratório, com abordagem quantitativa realizado nas maternidades do Hospital Universitário Clemente de Faria (HUCF) e Hospital Aroldo Tourinho (HAT), credenciado na IHAC, da cidade de Montes Claros, norte de Minas Gerais (MG).

Nas referidas instituições atuam 26 pediatras, nove residentes e cinco enfermeiros. A amostra do estudo foi constituída por 27 profissionais, destes 15 pediatras, oito residentes e quatro enfermeiros, que atenderam aos seguintes critérios de inclusão: trabalhar na instituição por no mínimo seis meses; e, na categoria enfermeiro, exercer função assistencial no setor. Houve perda de um profissional que se recusou em participar do estudo. Como critério de exclusão adotou-se: estar afastado do serviço por férias ou licença médica durante o período de coleta. Todos os participantes após serem esclarecidos dos objetivos do estudo, assinaram o Termo de Consentimento Livre e Esclarecido (TCLE) em duas vias ficando uma via com o entrevistado e a outra com a pesquisadora.

Foi utilizado um questionário estruturado intitulado "Questionário de avaliação dos critérios 155 
ISSN 2179-6750

reconhecidos por profissionais atuantes em alojamentos conjuntos acerca da complementação ou substituição do leite materno" como instrumento de coleta de dados. O mesmo foi elaborado pelos pesquisadores contendo informações sobre o perfil dos participantes e 13 perguntas estruturadas contemplando aspectos relacionados ao uso do complemento lácteo em alojamento conjunto. A fim de verificar se o conteúdo era adequado ao que se pretendia medir, o instrumento passou por um pré-teste com profissionais da área, de forma a realizar as adaptações necessárias.

A coleta dos dados foi feita por meio de questionário aplicado a pediatras, residentes em pediatria e enfermeiros atuantes em alojamento conjunto, no mês de outubro de 2013. As respostas às questões foram organizadas para serem respondidas por meio de uma escala de Likert. Essa escala foi apresentada com cinco graus de variação, sendo a resposta "não sei" considerada nula (grau 0), as demais foram pontuadas de forma variável sendo atribuída a pontuação máxima (4) para a resposta considerada correta (baseado na orientação do MS), e pontuação mínima (1), para a alternativa oposta, sendo os graus intermediários atribuídos às opções que se aproximavam dos extremos (graus 2 e 3). Em seguida, a escala foi apresentada aos especialistas da área.

Para a análise quantitativa os dados foram digitados no SPSS® (Statistical Package for the Social Science), versão 18.0, e posteriormente foi realizada estatística descritiva, utilizando medidas de tendência central para o score, obtido através da somatória das respostas obtidas em todos os questionários e montado um banco de dados a partir do qual se obteve a pontuação máxima de 36 e o mínimo de 26 pontos, em uma escala de 0 (pontuação mínima possível) a 52 (pontuação máxima possível) e encontrado uma média de 31.1. Foram excluídas desta somatória as questões 12 e 13 por tratar-se de questões relativas à percepção do participante sobre o uso de complemento lácteo.

O estudo obedeceu aos preceitos éticos da Resolução 466/2012 que regulamenta a realização de pesquisa envolvendo seres humanos. O projeto de pesquisa foi aprovado pelo Comitê de Ética em Pesquisa da Universidade Estadual de Montes Claros (CEP UNIMONTES) sob Parecer de $n^{\circ}$ $355.206 / 2013$.

\section{Resultados}

Dos 27 participantes, prevaleceu o sexo feminino, e, na categoria profissional, o médico pediatra. $\mathrm{O}$ tempo de trabalho na instituição variou de um a 15 anos, sendo a maioria entre cinco e nove anos, conforme apresentado na tabela abaixo (Tabela 1). 
Tabela 1. Caracterização da amostra segundo sexo, instituição, formação acadêmica, especialização, função e tempo de trabalho na instituição. Montes Claros, Minas Gerais, Brasil - 2013.

\begin{tabular}{|c|c|c|c|c|c|}
\hline Variáveis & Descrição & Especialização & Cargo/Função & $\mathrm{n}=\mathbf{2 7}$ & $\%$ \\
\hline \multirow[t]{2}{*}{ Gênero } & Masculino & - & - & 05 & 18,5 \\
\hline & Feminino & - & - & 22 & 81,5 \\
\hline \multirow[t]{2}{*}{ Instituição } & HUCF & - & - & 23 & 85,2 \\
\hline & HAT & - & - & 04 & 14,8 \\
\hline \multirow{5}{*}{ Formação } & Medicina & Pediatria & Médico & 15 & 55,6 \\
\hline & & Em curso & Residente & 07 & 25,9 \\
\hline & & Terapia Intensiva & Médico & 01 & 3,7 \\
\hline & Enfermagem & $\begin{array}{c}\text { Mestrado em Ciências } \\
\text { da Saúde }\end{array}$ & $\begin{array}{l}\text { Enfermeiro } \\
\text { assistencial }\end{array}$ & 01 & 3,7 \\
\hline & & $\begin{array}{c}\text { Residência } \\
\text { Multiprofissional em } \\
\text { Saúde da Família }\end{array}$ & $\begin{array}{l}\text { Enfermeiro } \\
\text { assistencial }\end{array}$ & 03 & 11,1 \\
\hline \multirow{3}{*}{$\begin{array}{l}\text { Tempo de } \\
\text { trabalho na } \\
\text { instituição }\end{array}$} & 1-4 anos & - & - & 08 & 29,6 \\
\hline & 5-9 anos & - & - & 12 & 44,4 \\
\hline & $10-15$ anos & - & - & 07 & 25,9 \\
\hline
\end{tabular}

O AM, em alguns casos, pode ser substituído pelo complemento lácteo. A causa pode advir do próprio RN ou da mãe. Estes casos são motivos considerados aceitáveis para o uso do mesmo, sendo estes: lactentes com galactosemia clássica; lactentes com doença da urina de xarope do bordo; Lactentes com fenilcetonúria; lactentes nascidos com menos de 1500g; lactentes nascidos com menos de 32 semanas de idade gestacional; lactentes com risco de hipoglicemia; mães com infecção pelo Human Immunodeficiency Virus (HIV); doença grave que impede a mãe de cuidar de seu filho, por exemplo, sepse; mães com infecção pelo HSV-1; mães que utilizam medicações (sedativas, psicoterápicas, anti-epiléticas e opiáceas), receberam iodo-131 radioativo, uso em excesso de iodofor tópico e mães em quimioterapia citotóxica; mães com abscesso mamário, portadoras de Hepatite B e C, mastite, tuberculose e uso de drogas lícitas e ilícitas.

Quando questionados sobre os motivos considerados aceitáveis para o uso de complemento lácteo, 85,2\% dos profissionais concordam totalmente. Em relação à indicação de uso de complemento lácteo em $\mathrm{RN}$ a termo com risco de hipoglicemia, 44,4\% dos participantes concordam parcialmente. Quanto aos lactentes com menos de 32 semanas ou muito baixo peso (menos de 1500 gramas) poderem receber complementação com fórmula por período limitado, 44,4\% concordam parcialmente. Em se tratando da indicação de complementação láctea em $\mathrm{RN}$ com doenças metabólicas, a maior parte (37\%) concorda totalmente em não usar o complemento lácteo em caso de galactosemia clássica. Em 48,1\% discordam parcialmente quanto ao aleitamento materno exclusivo (AME) em RN com fenilcetonúria. Quanto ao início da complementação láctea na 
ISSN 2179-6750

presença de quadro de hipogalactia percebida nas primeiras 24 horas, $37 \%$ concordam parcialmente (Tabela 2).

A tabela 3 retrata a indicação da complementação para RN em condição de patologias infectocontagiosas de transmissibilidade vertical. Em 100\% dos participantes há a discordância total quanto ao aleitamento misto em RN de mães soropositivas. Logo, a complementação láctea se faz indispensável. Houve a concordância total em 66,7\% dos participantes em não interromper o AME em casos de mães portadoras de hepatite $\mathrm{B}$ ou $\mathrm{C}$, quanto à suspensão permanente do $\mathrm{AME}$ para mães com herpes vírus tipo 1,70,4\% discordam totalmente.

Tabela 2. Indicação de complementação láctea em RN que apresentam doenças metabólicas. Montes Claros, Minas Gerais, Brasil - 2013. $(\mathrm{n}=27)$

\begin{tabular}{|c|c|c|c|c|c|c|c|c|c|c|}
\hline \multirow[t]{2}{*}{ Variáveis } & \multicolumn{2}{|l|}{ CT } & \multicolumn{2}{|c|}{ CP } & \multicolumn{2}{|c|}{ DT } & \multicolumn{2}{|c|}{ DP } & \multicolumn{2}{|l|}{ NS } \\
\hline & n & $\%$ & n & $\%$ & n & $\%$ & n & $\%$ & n & $\%$ \\
\hline $\begin{array}{l}\text { Motivos aceitáveis para o uso de } \\
\text { complemento lácteo. }\end{array}$ & 23 & 85,2 & 03 & 11,1 & 01 & 3,7 & 00 & 00 & 00 & 00 \\
\hline $\begin{array}{l}\text { Indicação de uso de complemento lácteo } \\
\text { em RN a termo com risco de } \\
\text { hipoglicemia. }\end{array}$ & 10 & 37,1 & 12 & 44,4 & 04 & 14,8 & 01 & 3,7 & 00 & 00 \\
\hline $\begin{array}{l}\text { Uso de complementação láctea por tempo } \\
\text { limitado em lactentes com menos de } 32 \\
\text { semanas ou muito baixo peso (menos de } \\
1500 \text { gramas). }\end{array}$ & 10 & 37,1 & 12 & 44,4 & 04 & 14,8 & 01 & 3,7 & 00 & 00 \\
\hline $\begin{array}{l}\text { Suspensão da complementação lactea em } \\
\text { RN com galactosemia clássica. }\end{array}$ & 10 & 37,1 & 02 & 7,4 & 06 & 22,2 & 02 & 7,4 & 07 & 25,9 \\
\hline $\begin{array}{l}\text { AME em casos de } \mathrm{RN} \text { com } \\
\text { fenilcetonúria. }\end{array}$ & 00 & 00 & 06 & 22,2 & 05 & 18,5 & 13 & 48,1 & 03 & 11,1 \\
\hline $\begin{array}{l}\text { Início de complementação láctea em } \mathrm{RN} \\
\text { com hipogalactia percebida nas primeiras } \\
24 \text { horas. }\end{array}$ & 05 & 18,5 & 10 & 37,1 & 04 & 14,8 & 08 & 29,6 & 00 & 00 \\
\hline
\end{tabular}

Tabela 3. Indicação de complementação láctea para RN em condição de doenças infectocontagiosas maternas. Montes Claros, Minas Gerais, Brasil - 2013. $(n=27)$

\begin{tabular}{|c|c|c|c|c|c|c|c|c|c|c|}
\hline \multirow[t]{2}{*}{ Variáveis } & \multicolumn{2}{|c|}{ CT } & \multicolumn{2}{|c|}{$\mathbf{C P}$} & \multicolumn{2}{|c|}{ DT } & \multicolumn{2}{|c|}{ DP } & \multicolumn{2}{|c|}{ NS } \\
\hline & n & $\%$ & $\mathbf{n}$ & $\%$ & $\mathbf{n}$ & $\%$ & $\mathbf{n}$ & $\%$ & $\mathbf{n}$ & $\%$ \\
\hline $\begin{array}{l}\text { Aleitamento misto em } \mathrm{RN} \text { de mães HIV } \\
\text { positivas. }\end{array}$ & 00 & 00 & 00 & 00 & 27 & 100 & 00 & 00 & 00 & 00 \\
\hline $\begin{array}{l}\text { Não interromper o AME em RN com } \\
\text { mães portadoras de Hepatite B ou C. }\end{array}$ & 18 & 66,7 & 04 & 14,8 & 04 & 14,8 & 01 & 3,7 & 00 & 00 \\
\hline $\begin{array}{l}\text { Suspender permanentemente o AME em } \\
\mathrm{HSV}-1^{1}\end{array}$ & 00 & 00 & 01 & 3,7 & 19 & 70,4 & 06 & 22,2 & 01 & 3,7 \\
\hline
\end{tabular}

$C T=$ Concordo Totalmente $; C P=$ Concordo Parcialmente $;$ DT = Discordo Totalmente $;$ DP = Discordo Parcialmente $;$ NS $=$ Não Sei . ${ }^{1}$ HSV-1 - Herpes Simplex Virus tipo 1

No que se refere a não suspensão em nenhuma hipótese da AME em bebês cuja mãe está em tratamento com quimioterapia citotóxica, $66,7 \%$ discordam totalmente. Com relação ao uso de 158 
ISSN 2179-6750

medicamentos, tais como drogas sedativas, psicoterápicas, antiepiléticas ou opiáceas, não constituírem barreira ao AME durante seu uso, 40,7\% dos participantes discordaram totalmente. Referente à frequência do uso de complemento lácteo na instituição de trabalho, 33,3\% discordaram parcialmente. O último ponto abordado foi sobre a existência de um protocolo específico que oriente a complementação láctea em RN na instituição. Com isso, 29,6\% dos participantes concordam totalmente e $25,9 \%$ discordaram parcialmente (Tabela 4 ).

Tabela 4. Promoção do uso de complementação láctea nas instituições de saúde e sua indicação para RN de mães em condição quimioterápica e uso farmacológico de controle. Montes Claros, Minas Gerais, Brasil 2013. $(n=27)$

\begin{tabular}{|c|c|c|c|c|c|c|c|c|c|c|}
\hline \multirow[t]{2}{*}{ Variáveis } & \multicolumn{2}{|c|}{ CT } & \multicolumn{2}{|c|}{ CP } & \multicolumn{2}{|c|}{ DT } & \multicolumn{2}{|c|}{ DP } & \multicolumn{2}{|c|}{ NS } \\
\hline & $\mathbf{n}$ & $\%$ & $\mathbf{n}$ & $\%$ & $\mathbf{n}$ & $\%$ & $\mathbf{n}$ & $\%$ & $\mathbf{n}$ & $\%$ \\
\hline $\begin{array}{l}\text { AME em RN com mães em tratamento } \\
\text { quimioterápico }\end{array}$ & 01 & 3,7 & 01 & 3,7 & 18 & 66,7 & 03 & 11,1 & 04 & 14,8 \\
\hline $\begin{array}{l}\text { Restrição do AME em mães usuárias de } \\
\text { medicamentos (sedativos, psicoterápicos, } \\
\text { antiepiléticas, opiáceas) }\end{array}$ & 03 & 11,1 & 06 & 22,2 & 11 & 40,7 & 07 & 26 & 00 & 00 \\
\hline $\begin{array}{l}\text { Frequencia do uso de complemento } \\
\text { lácteo na instituição de trabalho }\end{array}$ & 06 & 22,2 & 08 & 29,6 & 04 & 14,8 & 09 & 33,4 & 00 & 00 \\
\hline $\begin{array}{l}\text { Existência de protocolo que oriente a } \\
\text { complementação láctea em RN na } \\
\text { instituição }\end{array}$ & 08 & 29,6 & 04 & 14,8 & 06 & 22,2 & 07 & 26 & 02 & 7,4 \\
\hline
\end{tabular}

\section{Discussão}

A prática da amamentação configura-se como importante instrumento para a melhoria da saúde pública, uma vez que atua na redução da morbidade e mortalidade infantil e na prevenção e/ou proteção de doenças futuras, tais como o diabetes mellitus (DM), hipertensão arterial sistêmica (HAS), infarto agudo do miocárdio (IAM), acidente vascular encefálico (AVE), dentre outras. Entretanto, este efeito protetor do aleitamento pode diminuir substancialmente quando a criança recebe, além do leite materno, qualquer tipo de complementação alimentar ${ }^{7}$. Há evidências de que a utilização do complemento lácteo aumenta a probabilidade de interromper a amamentação ${ }^{8}$ e, por isso, esse uso só é recomendado em situações específicas ${ }^{5}$.

No período puerperal é de fundamental importância que a mulher sinta-se adequadamente assistida nas suas dúvidas e dificuldades, para que a mesma possa assumir com mais segurança o papel de mãe e provedora do alimento de seu filho, cabendo aos profissionais de saúde, o compromisso de ajudar essas mães de modo a tornar a amamentação um ato de prazer e não uma obrigação ${ }^{9}$. 
ISSN 2179-6750

Para orientar a ação profissional sobre a necessidade ou não da complementação e as situações em que a amamentação deve ser contraindicada, temporária ou permanentemente, a Organização Mundial de Saúde (OMS) elaborou um documento intitulado: Razões médicas aceitáveis para uso de substitutos do $\mathrm{AM}^{5}$. O MS adotou essa recomendação e a programou a partir do $6^{\circ}$ passo contido nos 10 passos para o sucesso do AM: $6^{\circ}$ passo - não dar ao RN nenhum outro alimento ou bebida além do leite materno, a não ser que tal procedimento tenha uma indicação médica ${ }^{5}$.

Neste estudo, a maioria dos profissionais concordou com a existência dessas situações específicas e consideraram como indicações de complementação láctea apenas RN cuja mãe seja HIV positiva. Em todas as outras situações, os participantes revelaram dúvidas em suas respostas, apesar de muitas vezes terem se aproximado da conduta mais recomendada para cada caso. No estudo realizado em Santa Maria, Rio Grande do Sul (RS) ${ }^{8}$, entre as razões de uso de complementos estavam complementação do leite humano $(66,7 \%)$, o valor nutricional $14,8 \%$, a facilidade de uso $3,7 \%$, perda de peso do lactente, $3,7 \%$ doença da mãe, 3,7\% dificuldade para amamentar 3,7\%, e internação hospitalar da criança 3,7\%.

A indicação para uso de fórmula láctea em RN com fatores de risco para hipoglicemia somente é recomendado se essa glicemia não melhorar com o AM, sendo este, então, considerado a primeira escolha como tentativa de estabilização do quadro; RN com menos de 32 semanas ou menos de $1500 \mathrm{~g}$ se enquadram na mesma situação, podendo fazer uso da complementação láctea por um período limitado 5 .

Neste estudo, menos da metade dos participantes considerou não ser recomendado o uso do complemento lácteo nesses casos. A maioria considerou parcial a afirmativa aproximando-se da análise esperada da questão. Em um estudo realizado no alojamento conjunto de um hospital em Belo Horizonte (MG), o risco para hipoglicemia em RN apareceu como a principal indicação de uso do complemento lácteo ${ }^{10}$.

Outras situações contempladas no documento da OMS na qual contraindicam o AM e tornao substituível pelo complemento lácteo são: RN com galactosemia clássica, fenilcetonúria, RN de mães em tratamento com quimioterapia e uso de determinados medicamentos, portadoras do vírus da Hepatite B ou C, HSV-1 e HIV ${ }^{5}$, conforme discutido abaixo.

A galactosemia clássica é uma doença metabólica hereditária que provoca deterioração neurológica progressiva, cataratas e alterações nos aparelhos digestivo e renal, características que podem aparecer logo no período pós-natal após ingestão de leite de origem animal, o diagnóstico precoce é fundamental para instalação do tratamento que consiste no uso de uma fórmula especial 
ISSN 2179-6750

isenta de galactose e este RN não deverá receber leite materno nem nenhum outro tipo de leite de origem animal ${ }^{11}$.

Um número significativo de participantes respondeu que não indicariam o complemento lácteo para os casos de galactosemia clássica, entretanto pôde-se observar um número significativo também de respostas como "não sei”, que indica um equilíbrio entre profissionais que adotariam uma conduta correta frente ao caso e profissionais ainda inseguros quanto a sua conduta.

A fenilcetonúria ocorre na incapacidade do organismo de transformar fenilalanina em tirosina, trazendo efeitos tóxicos para o sistema nervoso central (SNC). Tradicionalmente, no tratamento da doença suspende-se o AM e passa-se a usar uma fórmula láctea comercial especial, isenta ou com dosagem específica do aminoácido, pois, durante muito tempo, acreditou-se não ser segura a amamentação de bebês recém-diagnosticados com fenilcetonúria, devido à dificuldade de quantificar a ingestão de fenilalanina durante a mamada ao seio ${ }^{12}$.

Em estudo realizado em São Paulo, os autores concluíram que $80 \%$ dos lactentes conseguiram manter limites seguros da fenilalanina no organismo mostrando que há viabilidade da continuidade do AM no tratamento dessas crianças desde que esses níveis sejam rigorosamente ${ }^{12}$.

Neste estudo, a maioria dos participantes teve dúvida sobre a possibilidade de um RN com fenilcetonúria poder ser amamentado exclusivamente ao seio, isso pode ser explicado devido ao AM ser possível, entretanto não exclusivamente. A palavra "exclusiva" pode ter gerado dúvidas nos participantes, além de, em nossa prática, haver impossibilidade de acompanhamento desse bebê, e prevalecendo a recomendação de suspensão do AM nesses casos.

Situações de hipogalactia "real" são raras, visto que existe a produção do colostro desde o sexto mês de gestação e que este, através do início precoce da sucção pelo bebê, será ejetado mesmo antes da apojadura (descida do leite). Assim, o profissional deve conhecer a fisiologia da lactação, em especial como se comporta a produção láctea no período de puerpério imediato tendo condições de orientar a mãe sobre a presença deste leite e sobre o fato do RN utilizar-se de suas reservas até que ocorra a apojadura ${ }^{13}$.

Um bom manejo da situação consiste em intervenções que visem afastar fatores como a dor, o desconforto, o estresse, a ansiedade, o medo, a insegurança e a falta de autoconfiança materna que agem inibindo a liberação da ocitocina, prejudicando a saída do leite da mama ${ }^{4}$. Como fatores importantes para garantia da produção látea consideram-se: a frequência das mamadas, que deve ser de 8 a 10 vezes por dia, para desencadear o reflexo da prolactina; o início precoce da amamentação, de preferência na primeira meia hora de vida do bebê e o posicionamento e pega corretos ${ }^{1}$.

A recomendação para mães portadoras do HIV, é que se suspenda permanentemente a 161 
ISSN 2179-6750

amamentação e seja assegurada ao RN uma alimentação aceitável, factível, acessível, sustentável e segura, uma vez que o AM expõe o RN ao vírus ${ }^{5}$. Neste estudo todos os profissionais discordaram sobre a recomendação de aleitamento misto nestes casos (complemento lácteo + seio materno), indicando conhecimento sobre a necessidade de suspensão do AM. Resultado semelhante foi encontrado em estudo realizado em um Hospital Amigo da criança em Belo Horizonte, no qual todas as mães HIV positivas tiveram a amamentação suspensa, sendo iniciada a complementação láctea ${ }^{10}$.

A OMS recomenda que os casos de RN cujas mães sejam portadoras do vírus da hepatite B ou $\mathrm{C}$ podem ser amamentados, sendo que, para hepatite $\mathrm{B}$, o RN deve receber a imunoglobulina específica nas primeiras horas de vida e a primeira dose da vacina contra hepatite B nas primeiras 48 horas. Na infecção materna pelo vírus do HSV-1, a amamentação deve ser evitada, (de forma temporária), apenas se houver lesões ativas no mamilo ou proximidades estando em contato com a boca do bebê. Nesses casos a mãe pode retornar com a amamentação logo que as lesões estejam curadas. Na ausência de lesões o aleitamento deve ser promovido como a rotina ${ }^{5}$.

Neste estudo, mais da metade dos participantes concordou que não há a necessidade de interromper a amamentação nos casos acima mencionados, sendo estes: mães portadoras do vírus da hepatite B e hepatite $\mathrm{C}$.

A amamentação pode ainda precisar ser suspensa quando a nutriz necessitar de algum tipo de tratamento farmacológico com drogas sedativas, psicoterápicas, antiepiléticas, opiáceos ou em tratamento com quimioterapia ${ }^{5}$. Contudo, uma indicação criteriosa do tratamento materno e a seleção cuidadosa dos medicamentos geralmente permitem que a amamentação continue sem interrupção e com segurança, permitindo-se que mãe e criança usufruam dos benefícios do $\mathrm{AM}^{2}$. A maioria dos participantes deste estudo respondeu não concordar em suspender o AM em RN de mães em tratamento quimioterápico. Uma pequena parcela concordou que o uso de drogas sedativas, psicoterápicas, antiepiléticas e opiáceos não constituem barreira ao estabelecimento do AM.

Verificamos que, quando perguntados sobre ser frequente a complementação láctea na instituição em que atua, as respostas dos participantes foram mais frequentes entre as opções "concordo parcialmente" e "discordo parcialmente", indicando que estes profissionais possuem dúvidas em relação a essa questão. O mesmo ocorreu quanto à existência de um protocolo específico para complementação láctea dentro da instituição. A ocorrência de dúvidas referentes ao processo de trabalho pode indicar a necessidade de implementação constante da Educação Permanente em Saúde através de uma Educação Crítico-Reflexiva fundamental para a construção 
ISSN 2179-6750

de um novo olhar sobre questões como o $\mathrm{AM}^{14}$.

Em Terezinha, Piauí um estudo realizado em maternidades amigas da criança mostrou que as equipes de saúde dos hospitais foram treinadas nos cursos de 18 horas sobre o manejo e promoção do AM em maternidades amigas da criança ${ }^{15}$. Trata-se de um material destinado à capacitação das equipes dos hospitais para implementação da política de aleitamento, através de cursos de vinte horas voltados para aplicação de conhecimentos e habilidades dos profissionais de saúde em suas práticas cotidianas ${ }^{2}$. Ficou evidenciado que o sucesso da ação dos profissionais junto às mulheres depende da realização periódica de cursos acerca do tema, acreditando que com a incorporação de novos saberes sobre AM estes serão capazes de manter o interesse de seus interlocutores e de ampliar a importância de sua atuação ${ }^{15}$.

\section{Conclusão}

Os resultados do estudo permitem verificar que a principal razão reconhecida pelos entrevistados para a complementação alimentar ou substituição do AM foi a situação de RN cuja mãe é HIV positiva. Isso indica que estes profissionais estão preparados para situações críticas como é o HIV. Apesar de não ter prevalecido indicação do complemento lácteo para as demais situações, observou-se uma insegurança, bem como desconhecimento dos profissionais por meio de respostas como "não sei”, além da maioria ter sido respondida de forma parcial.

Acreditamos que em algum momento esta dúvida pode implicar no uso desnecessário do complemento e consequentemente na perda de todos os benefícios do AM, uma vez que o complemento lácteo é apontado como fator de risco para o abandono precoce da amamentação.

Reconhecemos que o complemento artificial lácteo pode auxiliar na nutrição de bebês que não podem ser amamentados ao seio materno por uma condição própria ou da mãe, entretanto o desconhecimento dessas condições pode levar ao uso deste em situações que poderiam ser mais bem manejadas pelo profissional de saúde. Recomendamos o investimento em treinamentos e manutenção da educação permanente preparando a equipe para atender as mais diversas situações, e a criação de um protocolo para maior controle e padronização das indicações de uso do complemento lácteo apoiados nas orientações do MS e da OMS.

Existem poucos estudos que avaliam a prevalência e duração do $A M$, entre RN que receberam complementação, em especial, durante a sua estadia no alojamento conjunto. Desse modo, espera-se que os resultados desta pesquisa possam subsidiar ações voltadas para promoção, apoio e proteção do AM considerando-se os pressupostos estabelecidos pela IHAC. 


\section{Referências}

1. Brasil. Ministério da Saúde. Secretaria de Atenção a Saúde. Departamento de Ações Programáticas e Estratégicas. II Pesquisa de Prevalência de Aleitamento Materno nas Capitais Brasileiras e Distrito Federal. Brasília, 2009.

2. Brasil. Ministério da Saúde. Secretaria da Atenção à Saúde. Departamento de Ações Programáticas e Estratégicas. Amamentação e uso de medicamentos e outras substâncias. Brasília, 2010.

3. Brasil. Ministério da Saúde. A iniciativa hospital amigo da criança no Brasil. 2010.

4. International Baby Food Action Network (IBFAN). Atualidades em amamentação. Março de 2009, no 44-5. Acesso em: 10/07/2013. Disponível em: http://www.ibfan.org.br

5. Organização Mundial da Saúde (OMS). Razões médicas aceitáveis para uso de substitutos do leite Materno. Genebra, 2009. Acesso em: 25/09/2012. Disponível em: http://whqlibdoc.who.int/hq/2009/WHO.

6. Pedras CTPA, Pinto EALC, Mezzacappa MA. Uso do copo e da mamadeira e o aleitamento materno em recém-nascidos prematuros e a termo: uma revisão sistemática. Rev Bras Saúde Matern Infant. 2008;8(2):163-9.

7. Silva DRN, Schneider AP, Stein RT. O papel do aleitamento materno no desenvolvimento de alergias respiratórias. Sci Med. 2009;19(1):35-42.

8. Moro GMB, Mesquita MO. Uso de fórmulas de partida e de seguimento por lactentes saudáveis em uma clínica pediátrica de Santa Maria, RS. EFDeportes.com, Revista Digital. 2011;16(155):1-9.

9. Araújo OD. Aleitamento materno: fatores que levam ao desmame precoce. Rev Bras Enferm. 2008;61(4):488-92.

10. Cerávolo AS, Araújo EB, Carvalho MIS, Maia WO, Souza EB, Grossmann SMC. Avaliação da adequada indicação de leite artificial em recém-nascidos em uma maternidade de referência de Minas Gerais. Rev UNINCOR. 2013;11(1):78-83.

11. Silva ASC, Cardoso IL. Diagnóstico da galactosemia clássica [Monografia]. Fernando Pessoa (PB), Faculdade de ciências da Saúde, Universidade Fernando Pessoa, 2008. Acesso em: 20/11/2013. Disponível em: http://bdigital.ufp.pt/bitstream/10284/929/2/24-34.pdf.

12. Lamônica DAC, Stump MV, Pedro KP, Rolim-Liporacci MC, Caldeira ACGC, AnastácioPessan FL et al. Acompanhamento do aleitamento materno no tratamento de crianças com fenilcetonúria. J Soc Bras Fonoaudiol. 2012;24(4):386-9.

13. Brasil. Ministério da Saúde. Secretaria de Atenção à Saúde. Departamento de Atenção 164 
ISSN 2179-6750

Básica. Saúde da criança - Nutrição infantil: aleitamento materno e alimentação complementar. Brasília, 2009.

14. Brasil. Ministério da Saúde. Secretaria de Atenção à Saúde. Departamento de Atenção Básica. Departamento de Ações Programáticas Estratégicas. Área Técnica de Saúde da Criança e Aleitamento Materno. Rede Amamenta Brasil. Brasília, 2009.

15. Ramos CV, Almeida JAG, Pereira LMR, Pereira TG. A iniciativa hospital amigo da criança sob a ótica dos atores sociais que a vivenciam em Teresina, Piauí. Rev Nutr. 2010; 23(6):1019-30. 